\title{
Effect of hand hygiene on infectious diseases in the office workplace: A systematic review
}

\author{
Paul N. Zivich MPH ${ }^{a}$, Abigail S. Gancz ${ }^{\text {b }}$, Allison E. Aiello PhD, MS a,c,* \\ a Department of Epidemiology, Gillings School of Global Public Health, University of North Carolina Chapel Hill, NC \\ ${ }^{\mathrm{b}}$ Department of Biostatistics, Gillings School of Global Public Health, University of North Carolina Chapel Hill, NC \\ ${ }^{\mathrm{c}}$ Carolina Population Center, University of North Carolina Chapel Hill, NC
}

Key Words:

Office

Hand hygiene

Infectious disease

Pandemic

\begin{abstract}
Background: Extensive data suggests that hand hygiene is a critical intervention for reducing infectious disease transmission in the clinical setting. However, it is unclear whether hand hygiene is effective at cutting down on infectious illnesses in non-clinical workplaces. The aim of this review is to assess the current literature concerning the effects of hand-washing interventions on infectious disease prevention among employees in nonclinical, office-based workplaces.

Methods: In compiling this review, PubMed, Scopus, and Business Source Premier were examined for studies published from 1960 through 2016.

Results: Eleven studies (eight experimental, two observational, one a simulation) were identified as eligible for inclusion. Hand-hygiene interventions at various levels of rigor were shown to reduce selfreported illness symptoms.

Conclusions: Hand hygiene is thought to be more effective against gastrointestinal illness than it is against respiratory illness, but no clear consensus has been reached on this point. Minimal hand-hygiene interventions seem to be effective at reducing the incidence of employee illness. Along with reducing infections among employees, hand-hygiene programs in the workplace may provide additional benefits to employers by reducing the number of employee health insurance claims and improving employee morale. Future research should use objective measures of hand hygiene and illness, and explore economic impacts on employers more fully.
\end{abstract}

Prevention of infectious disease in the office-based workplace is a vital objective because such settings hold high potential for contact between healthy and ill individuals, and they harbor numerous contaminated fomites. Further, businesses with such workplaces may suffer substantial economic losses due to preventable illness. In the Occupational Safety and Health Administration guidelines on workplace influenza pandemic preparedness, hand hygiene plays a central role in mitigating risk in all types of workplaces. ${ }^{1}$ Aside from their potential as pandemic sites, workplaces are key locations for exposure to seasonal infectious diseases.

\footnotetext{
* Address correspondence to Allison E. Aiello, PhD, 135 Dauer Dr, 2101C McGavranGreenberg Hall, Chapel Hill, NC 27599.

E-mail address: aaiello@unc.edu (A.E. Aiello).

No organization sponsored the research.

Conflicts of Interest: P.N.Z. and A.E.A. have received funding from GOJO Industries Inc. (Akron, OH) for a related project. GOJO Industries Inc. did not provide funding for this systematic review and was not involved in the conception, selection, review, or analysis of this project.
}

Almost 20\% of known contacts with visibly ill individuals occurs in the workplace, ${ }^{2}$ and each year, $50 \%$ of workers develop a respiratory ailment. ${ }^{3}$ Furthermore, these contacts in the workplace were associated with 11 times the risk of gastrointestinal (GI) illness and four times the risk of respiratory illness among those exposed, compared with those who were not exposed during that week or the previous week.

These studies suggest that the workplace is an important location for infectious disease propagation. Dynamics of infectious disease transmission are also affected by office design and equipment sharing. Office spaces with an open floor plan have higher numbers of disease-related absences, ${ }^{4}$ and employees with shared offices have more episodes of the common cold compared to employees in private offices. ${ }^{5}$ Structural factors, such as ventilation systems, influence transmission, but much remains to be determined. ${ }^{6}$ Certain shared items at worksites have the potential to be important fomites, such as phones, keyboards, and desks. These have been recognized as key sources for the spread of infection in clinical settings $\mathrm{s}^{7,8}$ and have been shown to be contaminated in nonclinical settings. ${ }^{9,10}$ 
The economic loss at the employee level due to infectious diseases is a function of two factors- absenteeism and presenteeism. Absenteeism, in this context, means missing work due to illness. Influenza-like illness causes an estimated $<1-4.3$ days of missed work per individual. ${ }^{11}$ Influenza is estimated to cost the United States $\$ 16.3$ billion in lost productivity and loss of life annually, ${ }^{12}$ and influenza accounts for only $5 \%-20 \%$ of all illness-related absences, ${ }^{13}$ so the overall impact of infectious diseases is likely substantial. Less is known about the impact of GI illness, but evidence indicates that it is associated with higher rates of work absence. ${ }^{14,15}$ Presenteeism, or attending work while ill, has been observed to have negative impacts on employee mood and productivity, ${ }^{16-19}$ but strategies to reduce this practice are under-studied. ${ }^{20} \mathrm{~A}$ cross-sectional study found that $50 \%$ of all participants reported always attending work while symptomatic for a cold, in $2008 .{ }^{21}$ A decrease to $40.9 \%$ was observed after a hygiene campaign was conducted in response to the $2009 \mathrm{H} 1 \mathrm{~N} 1$ pandemic. Another study found that less than one third of employees with respiratory infections take sick leave. ${ }^{3,15}$ In addition to effects on the individual, presenteeism increases the potential for transmission of infections to coworkers. ${ }^{22}$ In total, presenteeism has been estimated to account for up to $66.4 \%$ of a $\$ 25$ billion of annual economic loss in the United States, due to the common cold alone. ${ }^{23}$ Clearly, reductions in absenteeism and presenteeism are likely to have substantial economic benefits and lead to improvements in population health. One way to potentially reduce infection rates and minimize their spread is through increased hand hygiene.

Hand hygiene has been shown to be an important means of preventing respiratory and GI illness in both clinical ${ }^{24-26}$ and community settings such as schools and households. ${ }^{27}$ Less is known about the impact of hand hygiene in the office-based workplace. This setting is a promising arena in which to employ hand-hygiene interventions because employed adults spend about 7.6 hours each day doing work-related activities, and $82 \%$ of employees complete at least some of their work at the workplace. ${ }^{28}$ Moreover, employees are often a captive audience during work hours, and employers have an economic stake in the health of their employees.

The primary objective of this systematic review was to assess the impact of hand hygiene on infectious disease risk among employees in nonclinical, office-based workplaces. We discuss types of hand-hygiene interventions that are effective and the potential economic impact of such interventions on employers. The purpose of this review is to inform infection-control policies, identify effective strategies to influence hand hygiene, and highlight gaps in the literature.

\section{METHODS}

We searched PubMed, Scopus, and Business Source Premier (BSP), using title/abstract/MeSH (medical subject heading)/other term fields, including publications up to September 2016. Articles published after that date, up to July 27, 2017, were evaluated for additional studies that met the criteria and were published after the start of the review. The protocol and study process were registered with the International Prospective Register of Systematic Reviews (PROSPERO: CRD42016050285) on October 26, 2016. The PRISMA (Preferred Reporting Items for Systematic Review and Meta-Analyses) guidelines for literature search and presentation of results were followed. ${ }^{29}$

\section{Search strategy}

The primary search strategy included any search terms from categories 1,2 , or 3 (Table 1, Column 1 ). No restrictions were placed on publication date or language. Since BSP is a database of predominantly business, not medical, publications, a secondary search strategy was used to minimize the potential to miss articles. The second search of BSP used general illness terms (Table 1, Column 2 ), rather than the more-specific terms used in the primary search. The secondary BSP search added 11 additional articles to our search results. A manual search of references of included studies was performed to identify any articles missed by our search.

\section{Eligibility criteria}

To be included, studies had to meet three criteria: (1) be located in an office-based (nonclinical, non-food industry) workplace; (2) include a hand-hygiene measure; and (3) explore infectious disease outcomes. Studies examining food industry employees were excluded from the systematic review because these businesses have different regulations regarding hand hygiene than do office-based workplaces. Additionally, studies without a focus on employee hand hygiene and risk of infection (e.g., school-based studies focusing on students) were excluded. Only nonclinical workplaces were included, since risk of exposure to infectious illness and handhygiene requirements differ from those in clinical settings. Clinical workplaces included hospitals, medical schools, and doctor and dentist offices. The infectious outcomes included disease rates and economic cost-benefit related to infectious disease. No exclusions were made based on study design, hand-hygiene measure, or outcome measure.

Table 1

Terms used for database searches

\begin{tabular}{|c|c|c|}
\hline & PubMed/Scopus/Business Source Premier (1) & Business Source Premier (2) \\
\hline Category 1 : hand hygiene & 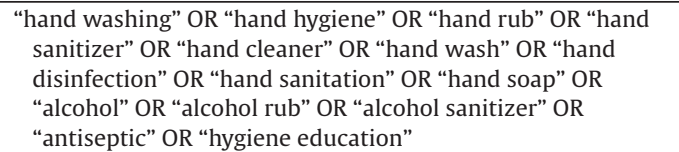 & $\begin{array}{l}\text { "hand washing" OR "hand hygiene" OR "hand rub" OR "hand } \\
\text { sanitizer" OR "hand cleaner" OR "hand wash" OR "hand } \\
\text { disinfection" OR "hand sanitation" OR "hand soap" OR } \\
\text { "alcohol" OR “alcohol rub" OR "alcohol sanitizer" OR } \\
\text { "antiseptic" OR "hygiene education" }\end{array}$ \\
\hline Category 2: workplace & $\begin{array}{l}\text { "workplace" OR “work" OR “office” OR “occupation” OR } \\
\text { “offices" OR “work site” OR “work place" OR “job site” OR } \\
\text { "worksite" }\end{array}$ & $\begin{array}{l}\text { “workplace” OR “work" OR “office” OR “occupation” OR } \\
\text { "offices" OR “work site” OR “work place” OR “job site” OR } \\
\text { "worksite" }\end{array}$ \\
\hline Category 3: infectious disease & $\begin{array}{l}\text { “cold” OR “diarrhea” OR “diarrhoea” OR “respiratory” OR } \\
\text { "infectious disease" OR “infectious illness” OR “infection” OR } \\
\text { "infect" OR “prevent" OR “prevention" OR “morbidity” OR } \\
\text { "communicable disease" OR “vomiting” }\end{array}$ & "health” OR “illness” OR “disease” \\
\hline
\end{tabular}

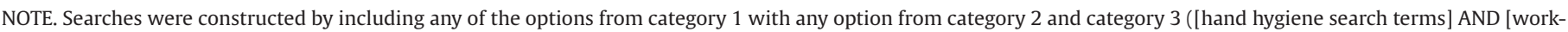
place search terms] AND [infectious disease search terms]). Search 2 for Business Source Premier included an additional 11 studies for review. 
Study selection

Two independent reviewers (two of the authors, PNZ \& ASG) screened identified studies by title, followed by a review of abstracts. The included studies then underwent a full text review. If consensus was not reached, the reviewers held a discussion, and if consensus still was not reached, a final decision was made by the third author (AEA). As recently recommended for systematic reviews, ${ }^{30}$ neither reviewer was a content expert in hand hygiene. From the final included studies, references were manually searched and screened using the same process.

\section{RESULTS}

\section{Search strategy}

The initial search returned 3545 unique studies; 37 articles were eligible after title and abstract screening, and of these, 9 met the inclusion criteria. The references of the selected articles were reviewed for additional studies that met the criteria. The final search, conducted in July of 2017, identified one additional article that had been published after the start of the review. Another eligible article, not identified by our search or in the references of other articles, was identified by searching for a citation regarding infections in offices. In total, 11 studies were included for the systematic review (Fig 1). Eight are experimental studies, two are observational studies, and one is a simulation-based study (Table 2).

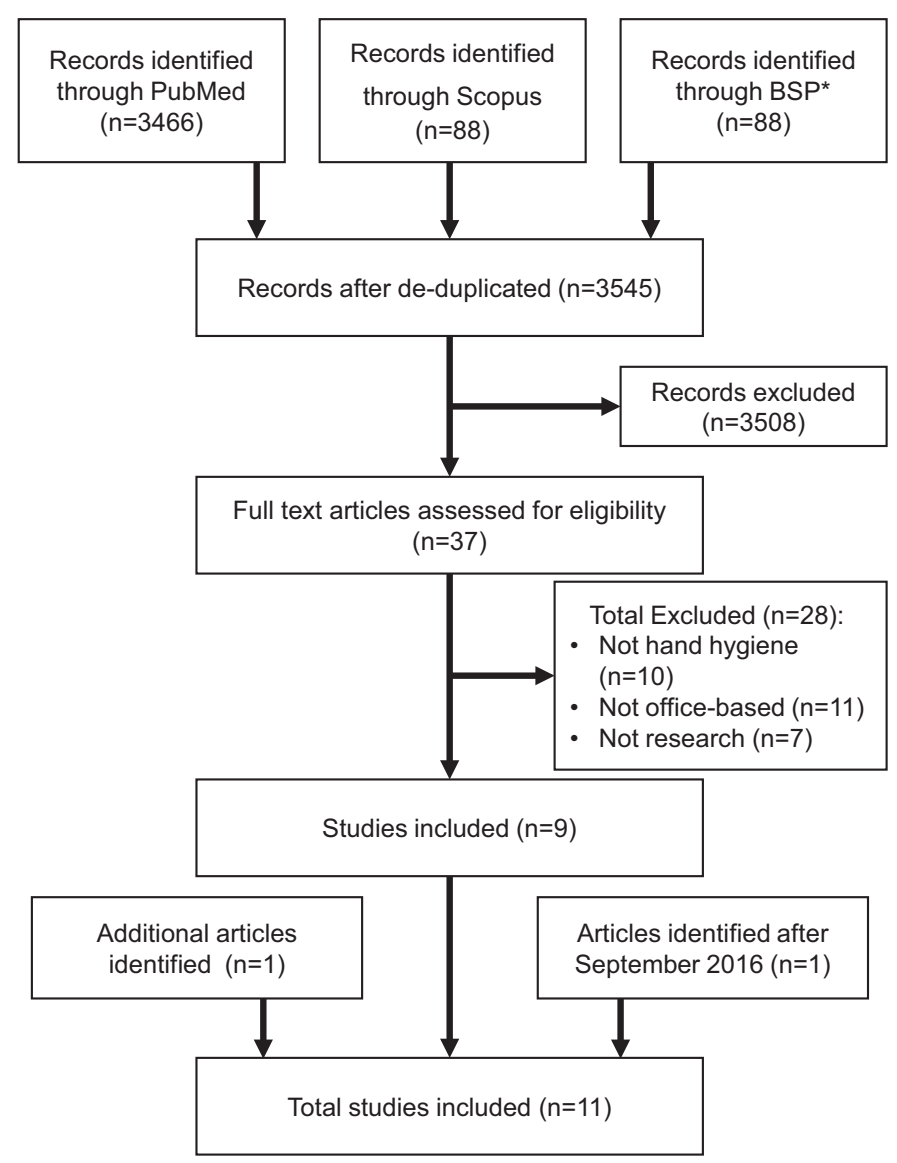

Fig 1. Flowchart of article selection. *BSP: Business Source Premier.

\section{Experimental designs}

Seven of the experimental studies were randomized control trials (RCTs), and one was a pre/post-test study. Of the seven RCTs, four were unique trials conducted on hand-hygiene and infectious disease outcomes. One trial took place in a German university and government administrative offices, ${ }^{31,42}$ one in a Finnish corporation, ${ }^{32-34}$ one in a U.S. midwestern government building, ${ }^{35}$ and one in a U.S. midwestern health insurance company. ${ }^{36}$ The pretest-posttest study was conducted in a southern U.S. corporate office ${ }^{37}$ (Table 3).

The RCT in Germany was randomized on an individual level, matching for customer and archival paper document contact. Intervention enrollees $(n=64)$ were provided with a hand-sanitizing rub in dispensers, instructed when to use the rub, and encouraged to use it at least five times daily. Controls $(n=65)$ received no intervention. The primary outcomes were reduction in self-reported illness $^{42}$ and sustainability of hand-washing practices by employees. ${ }^{31}$ Participants were contacted once a month to report general illness symptoms. The researchers found that the intervention group had significantly reduced odds of contracting a common cold (odds ratio $[\mathrm{OR}]=0.35 ; 95 \% \mathrm{CI}: 0.17,0.71)$, a fever $(\mathrm{OR}=0.38 ; 95 \% \mathrm{CI}: 0.14,0.99)$, and a cough $(\mathrm{OR}=0.45 ; 95 \% \mathrm{CI}$ : $0.22,0.91)$; they also had fewer absences from work due to diarrhea $(\mathrm{OR}=0.11 ; 95 \% \mathrm{CI}: 0.01,0.93) .{ }^{42}$ Of all employees in the intervention arm, 19\% reported following the recommended five times daily, at work, hand hygiene for the duration of the RCT. No assessment of hand hygiene of controls was conducted. Over half of the employees in the intervention favored continued use of hand-hygiene products after the study ended.

The RCT in Finland was conducted among six corporate offices. ${ }^{32}$ These sites were subdivided, matched on risk factors, and clusterrandomized to one of three groups: soap and water $(n=257)$; alcohol-based hand sanitizer $(n=202)$; or control $(n=224)$. Participants in the two intervention arms of the trial received similar hand-hygiene instructions, advice on reducing the spread of illness, and soap/alcohol dispensers to use at home. Controls were instructed to maintain their current hygiene habits.

The primary outcomes were respiratory illness and GI illness reported per week. Participants reported symptoms weekly via an online questionnaire. Due to the emergence of pandemic 2009 H1N1 influenza ( $\mathrm{pH} 1 \mathrm{~N} 1)$, the trial outcomes were split into prior pH1N1 and after pH1N1. The authors observed a 16.7\% reduction $(P=.002)$ in illness episodes per week in the soap-and-water handwashing group, compared with the control group, prior to $\mathrm{pH} 1 \mathrm{~N} 1 .^{33}$ When outcomes were subdivided into respiratory and GI illness, a statistically significant $15.9 \%$ reduction occurred in respiratory illness episodes per week (only before the occurrence of pH1N1), and a $25 \%$ reduction occurred in GI illness episodes per week for the full follow-up. No statistically significant reduction in either illness type was observed in comparisons of the alcohol-based hand sanitizer group and the control group over any time periods. In the control group, a significant reduction was seen in the number of illness episodes reported after $\mathrm{pH} 1 \mathrm{~N} 1$, compared with before $\mathrm{pH} 1 \mathrm{~N} 1$ $(P=.005)$.

A reanalysis of the data was conducted in which information was used on self-reported exposures to individuals with respiratory or GI illness. This analysis revealed that the soap-and-water intervention arm minimized GI illness, independent of reported exposures to ill individuals (risk ratio $(\mathrm{RR})=0.74$; $95 \% \mathrm{CI}$ : $0.51,1.05) .{ }^{34}$ Soapand-water hand hygiene was only marginally associated with prevention of respiratory illness, and prevention was strongest when there were no reported exposures. No effect was observed in the alcohol-based hand-rub intervention arm for either outcome. This analysis did not stratify between pre- and post-pH1N1, which the authors $^{34}$ acknowledge is a possible reason for the difference in results from those of the prior analysis. 
Table 2

Summaries of included articles

\begin{tabular}{|c|c|c|c|c|c|c|c|}
\hline Citation & Country & Office type & Type of study & Study Period & Sample Size* & Intervention & Major Findings \\
\hline Hubner $\mathrm{NO}^{31}$ & Germany & $\begin{array}{l}\text { Government and } \\
\text { university offices }\end{array}$ & Randomized trial & $\begin{array}{l}\text { March 2005-April } \\
2006\end{array}$ & $\begin{array}{l}134 \\
(64,65)\end{array}$ & $\begin{array}{l}\text { Instructions for proper Use, } \\
\text { frequency ( } 5 x \text { daily), } \\
\text { provided alcohol hand } \\
\text { sanitizer }\end{array}$ & $\begin{array}{l}\text { Intervention significantly reduced odds of experiencing symptoms } \\
\text { (common cold, fever, coughing) } \\
\text { Intervention significantly reduced odds of being absent due to } \\
\text { diarrhea but significant increase in odds for absent due to } \\
\text { bronchitis }\end{array}$ \\
\hline Hubner $\mathrm{NO}^{42}$ & Germany & $\begin{array}{l}\text { Government and } \\
\text { university offices }\end{array}$ & Randomized trial & $\begin{array}{l}\text { March 2005-April } \\
2006\end{array}$ & 64 & & $\begin{array}{l}\text { 78.1\% of monthly questionnaires of intervention group met the } \\
\text { recommended } 3 \times \text { per day disinfections } \\
45 \% \text { complied with hand hygiene time of at least } 30 \text { seconds } \\
56.4 \% \text { favored further Use of disinfectants at workplace }\end{array}$ \\
\hline Savolainen-Kopra $\mathrm{C}^{32}$ & Finland & Corporate offices & $\begin{array}{l}\text { Randomized } \\
\text { clU.S.ter trial }\end{array}$ & $\begin{array}{l}\text { January 2009-May } \\
2010\end{array}$ & $\begin{array}{l}683 \\
(257,202,224)\end{array}$ & $\begin{array}{l}\text { Both intervention arms } \\
\text { were given hand hygiene }\end{array}$ & - \\
\hline Savolainen-Kopra C 33 & Finland & Corporate offices & $\begin{array}{l}\text { Randomized } \\
\text { clU.S.ter trial }\end{array}$ & $\begin{array}{l}\text { January 2009-May } \\
2010\end{array}$ & $\begin{array}{l}683 \\
(257,202,224)\end{array}$ & $\begin{array}{l}\text { products for Use at home, } \\
\text { hand hygiene } \\
\text { instructions, infection } \\
\text { prevention instructions } \\
\text { Alcohol sanitizer arm } \\
\text { received alcohol sanitizer } \\
\text { dispensers at desks and }\end{array}$ & $\begin{array}{l}\text { Soap and water intervention arm has a significant reduction in } \\
\text { infection incidence overall }(6.7 \%, P=0.04) \text { and prior to pdmH1N1 } \\
(16.7 \%, P=0.002) \\
\text { No significant reduction in alcohol-based sanitizer intervention } \\
\text { arm } \\
\text { Soap and water intervention arm had significantly higher reported } \\
\text { sick leave episodes }(P=0.004) \text { and absences }(P=0.009)\end{array}$ \\
\hline Hovi $\mathrm{T}^{34}$ & Finland & Corporate offices & $\begin{array}{l}\text { Randomized } \\
\text { clU.S.ter trial }\end{array}$ & $\begin{array}{l}\text { January 2009-May } \\
2010\end{array}$ & $\begin{array}{l}683 \\
(257,202,224)\end{array}$ & bathroom & $\begin{array}{l}\text { The soap and water intervention arm had a risk of } 0.74(0.51,1.05) \\
\text { for GI illness compared to the control arm } \\
\text { Respiratory illness risk was only reduced when no exposure to a } \\
\text { symptomatic individual was reported ( } \mathrm{RR}=0.6895 \% \mathrm{CI} \text { : } 0.55 \text {, } \\
0.82 \text { ) } \\
\text { No protective effects were seen in the alcohol rub intervention arm }\end{array}$ \\
\hline Thompson $\mathrm{SJ}^{37}$ & U.S. & Corporate offices & Pretest-posttest & $\begin{array}{l}\text { December 2012- } \\
\text { February } 2013\end{array}$ & 681 & $\begin{array}{l}\text { Hand hygiene products } \\
\text { placed at employee } \\
\text { desks, common } \\
\text { workspaces, and critical } \\
\text { points, educational } \\
\text { materials, team point } \\
\text { system for to encourage } \\
\text { participation }\end{array}$ & $\begin{array}{l}\text { A } 37 \% \text { reduction in detected ATP on measured office surfaces } \\
\text { Reduction in days absent due to minor illness (median } 1 \text { day to } \\
\text { median } 0.87 \text { days) over } 30 \text { day period } \\
\text { A nonsignificant reduction in average medical service costs due to } \\
\text { minor illness ( } \$ 45.96 \text { to } \$ 32.88 \text { ) over six month period }\end{array}$ \\
\hline Stedman-Smith $\mathrm{M}^{35}$ & U.S. & Government offices & $\begin{array}{l}\text { Randomized } \\
\text { clU.S.ter trial }\end{array}$ & $\begin{array}{l}\text { February 2013- } \\
\text { June } 2013\end{array}$ & $\begin{array}{l}324 \\
(131,193)\end{array}$ & $\begin{array}{l}\text { Hand hygiene training } \\
\text { video ( } 5 \text { minutes), } \\
\text { posters, alcohol sanitizer } \\
\text { dispensers, personal } \\
\text { sanitizer dispensers }\end{array}$ & $\begin{array}{l}\text { Intervention significantly reduced combined respiratory tract/GI } \\
\text { illness symptoms } \\
\text { (IRR }=0.69,95 \% \text { CI: } 0.49-0.98 \text { ) } \\
\text { No significant reduction in lost work days (IRR }=0.79,95 \% \mathrm{CI} \text { : } \\
0.51-1.22 \text { ) } \\
\text { Hand hygiene score, agreement with hygiene expert score, and } \\
\text { reported frequency of hand sanitizer use compared to soap and } \\
\text { water similar between intervention and control }\end{array}$ \\
\hline Arbogast JW ${ }^{36}$ & U.S. & Corporate offices & $\begin{array}{l}\text { Randomized } \\
\text { clU.S.ter trial }\end{array}$ & $\begin{array}{l}\text { February 2014- } \\
\text { March } 2015\end{array}$ & $\begin{array}{l}1132 \\
(525,607)\end{array}$ & $\begin{array}{l}\text { Alcohol sanitizer } \\
\text { dispensers, personal } \\
\text { sanitizer dispensers, } \\
\text { sanitizing wipes }\end{array}$ & $\begin{array}{l}\text { Intervention significantly reduced hand hygiene preventable } \\
\text { health care claims }(24.3 \%, P=0.016) \\
\text { Intervention not associated with less Use of paid time off }(P= \\
0.344) \\
\text { Intervention increased reported hand hygiene practices, sense of } \\
\text { control, satisfaction with employer }(P<0.05)\end{array}$ \\
\hline Stedman-Smith $\mathrm{M}^{39}$ & U.S. & Bank offices & Observational & March 2011 & 159 & - & $\begin{array}{l}\text { TPB constructs were associated with hand hygiene } \\
60 \% \text { of survey participants reported at least one illness symptom } \\
\text { in prior } 30 \text { days }\end{array}$ \\
\hline Stedman-Smith $\mathrm{M}^{40}$ & U.S. & University offices & Observational & $\begin{array}{l}\text { March 2012-April } \\
2012\end{array}$ & 361 & - & $\begin{array}{l}\text { TPB constructs were associated with hand hygiene } \\
\text { Hand hygiene reduced odds of reporting illness } \\
\text { (OR }=0.55,95 \% \mathrm{CI}: 0.30-0.98)\end{array}$ \\
\hline Beamer PI ${ }^{41}$ & U.S. & General office & Simulation & - & - & $\begin{array}{l}\text { Facial tissues, hand } \\
\text { sanitizer, sanitizing } \\
\text { wipes, Use instructions }\end{array}$ & $\begin{array}{l}\text { Intervention would reduce rotavirU.S. and rhinovirU.S. infections } \\
\text { by } 77 \% \\
(P<0.0001)\end{array}$ \\
\hline
\end{tabular}

GI, gastrointestinal; IRR, incidence rate ratio; $R R$, risk ratio; TPB, Theory of Planned Behavior.

*Numbers in parentheses indicate the number of individuals randomized to each arm of the trial. 
Table 3

Strengths and weaknesses of included articles

\begin{tabular}{|c|c|c|}
\hline Study (first author) & Strengths & Weaknesses \\
\hline Hubner $^{31,42}$ & $\begin{array}{l}\text { - Individual randomization based on customer contact and } \\
\text { paper document contact } \\
\text { - Assessed skin problems in participants } \\
\text { - Assessed employee attitudes }\end{array}$ & $\begin{array}{l}\text { - Self-reported hand hygiene } \\
\text { - Self-reported outcomes } \\
\text { - No measure of hand hygiene in controls } \\
\text { - One month between follow-up surveys } \\
\text { - Small sample size }\end{array}$ \\
\hline Savolainen-Kopra ${ }^{32,33}$ & - Cluster randomized trial & - Self-reported hand hygiene \\
\hline $\mathrm{Hovi}^{34}$ & $\begin{array}{l}\text { - Matched clusters on risk factors } \\
\text { - Compared soap and water, and alcohol sanitizer, to control } \\
\text { - Weekly follow-up } \\
\text { - Long duration (16 months) }\end{array}$ & $\begin{array}{l}\text { - Self-reported outcomes } \\
\text { - Contamination due to } 2009 \text { influenza pandemic } \\
\text { - Potential leakage of intervention between arms }\end{array}$ \\
\hline Thompson $^{37}$ & $\begin{array}{l}\text { - Assessed objective proxy for bacterial contamination of surfaces } \\
\text { - Economic assessment }\end{array}$ & $\begin{array}{l}\text { - Self-reported hand hygiene } \\
\text { - Self-reported absence } \\
\text { - No measure of subclinical employee illness }\end{array}$ \\
\hline Stedman-Smith ${ }^{35}$ & $\begin{array}{l}\text { - Cluster randomized } \\
\text { - Matched based on department size }\end{array}$ & $\begin{array}{l}\text { - Self-reported hand hygiene } \\
\text { - Self-reported outcomes } \\
\text { - One month between follow-up surveys }\end{array}$ \\
\hline Arbogast $^{36}$ & $\begin{array}{l}\text { - Objective measure of hand hygiene } \\
\text { - Objective measure of infectious illness } \\
\text { - Economic assessment } \\
\text { - Assessed only impact in difference of availability of hand-hygiene } \\
\text { products } \\
\text { - Compared to control and historical data of intervention group }\end{array}$ & $\begin{array}{l}\text { - Global measure of hand hygiene } \\
\text { - No measure of subclinical employee illness } \\
\text { - Different public transportation use between trial arms }\end{array}$ \\
\hline Stedman-Smith ${ }^{40}$ & $\begin{array}{l}\text { - Focus on constructs impacting hand-hygiene behavior } \\
\text { - Explored real-world hand-hygiene practices }\end{array}$ & $\begin{array}{l}\text { - Observational } \\
\text { - Self-reported hand hygiene } \\
\text { - Self-reported outcome } \\
\text { - Single timepoint, prior } 30 \text { days }\end{array}$ \\
\hline Stedman-Smith ${ }^{39}$ & $\begin{array}{l}\text { - Focus on constructs impacting hand-hygiene behavior } \\
\text { - Explored real-world hand-hygiene practices }\end{array}$ & $\begin{array}{l}\text { - Observational } \\
\text { - Self-reported hand hygiene } \\
\text { - Self-reported outcome } \\
\text { - Single timepoint, prior } 30 \text { days } \\
\text { - No reported association }\end{array}$ \\
\hline Beamer $^{43}$ & $\begin{array}{l}\text { - Based on randomized trial with bacteriophage tracers } \\
\text { - Well measured contamination levels of fomites and hands in office setting } \\
\text { - Adapt a previous mathematical model }\end{array}$ & $\begin{array}{l}\text { - Large number of estimated parameters } \\
\text { - Weak evidence for multiple parameters } \\
\text { - No parameters for respiratory transmission }\end{array}$ \\
\hline
\end{tabular}

The pretest-posttest study in a U.S. corporate office $(n=681)$ was a pilot test of a hygiene-based intervention. ${ }^{37}$ The intervention program was conducted for 90 days. The intervention consisted of three parts: hand and surface sanitizers were placed on employee desks, common workspace areas, and critical locations; educational materials using protection motivation theory were distributed over the course of the intervention program; and employees were put into teams, with points awarded for germ reduction. The outcomes of the study were as follows: an indicator of bacterial contamination (adenosine triphosphate, a biochemical used for energy storage and use) detected on surfaces; self-reported workplace absence due to minor illness; and medical claims for defined infectious disease diagnoses.

The authors reported a 37\% decrease in detected adenosine triphosphate across all tested surfaces after the intervention. The time between pre- and post-measures for these outcomes was not clearly presented, and no information was provided regarding environmental cleaning. Comparing the 30 days before versus after the intervention, a statistically significant reduction in days absent was observed, with a median of 1 day absent decreasing to a median of 0.87 days absent. The average medical cost for employees decreased from $\$ 45.96$ to $\$ 32.88$, in the 6 months before versus after the test, though this difference was not statistically significant. Although self-reported information on hand hygiene was collected, it was not reported.

For the RCT in the U.S. government offices, 18 departments were cluster randomized to intervention $(n=131)$ or control $(n=193){ }^{35}$ The intervention arm received personal bottles of hand sanitizer, installation of hand-sanitizer dispensers, and motivational posters. They watched a short video on hand hygiene. The control arm watched a video regarding effective communication with healthcare providers. Educational posters were placed around department common areas regarding the video viewed by either group. Surveys were sent out monthly to assess self-reported compliance with hand washing suggestions and self-reported illness/lost work days. The primary outcomes of the study were respiratory and GI illness and lost work days due to illness. The authors found that the handwashing intervention significantly reduced the incidence of respiratory or GI illness in the intervention group (incidence rate ratio [IRR] $=0.69 ; 95 \% \mathrm{CI}: 0.49,0.98$ ), but not lost work days due to illness (IRR $=0.79 ; 95 \% \mathrm{CI}$ : $0.51,1.22$ ). No significant difference was found between the intervention and control groups in reported hand-hygiene performance score or use of hand sanitizer at least $25 \%$ of the time, compared with soap and water.

The RCT in a U.S. health insurance company was cluster randomized to either intervention (two office buildings, $n=525$ ) or control (one office building, $\mathrm{n}=607$ ). ${ }^{36}$ The outcomes were the number of health insurance claims for select conditions and the number of sick episodes, based on unscheduled, paid time off. In the intervention offices, alcohol-based sanitizer dispensers were placed in high-traffic areas/common areas, and individual alcohol hand-sanitizer bottles and hand wipes were placed in each cubicle. Both the intervention and control groups received identical handhygiene education and hand-washing posters placed in bathrooms. The intervention group had a statistically significant reduction in the number of health insurance claims compared with the control group (24.3\%; $P=.016)$. This effect remained after historical insurance claim data from the prior 4 years were factored into the analysis. The intervention group had a nonsignificant reduction in absences $(7.7 \% ; P=.344)$. Additionally, the authors estimated the amount of hand washing required to see this effect by measuring the hand-washing products before and after the intervention. Levels 
of use required to see this effect were 1.8 to 3 times per day for sanitizer, 2.1 to 4.4 times per day for soap, and 1.4 to 1.5 sanitizing wipes per week. The estimates were based on global average use and not on individual-level average use of the hand-hygiene products. The authors also reported that employee attitudes toward hand hygiene improved, and reported hand-hygiene compliance increased, as did the perception that the company cared about employee well-being.

\section{Observational studies}

Of the two cross-sectional surveys conducted by StedmanSmith et al. ${ }^{39,40}$, the authors tested whether the Theory of Planned Behavior (TPB) predicted hand-washing habits in Ohio bank employees $(\mathrm{n}=159)^{39}$ and Midwestern U.S. public university employees $(\mathrm{n}=361) \cdot{ }^{40}$ Information on hand-hygiene practices and illness were self-reported by participants via e-mail. Among both bank and university employees, the constructs of TPB (underlying attitudes, subjective norms, and perceived control) were associated with handhygiene performance. To change hand-hygiene behavior, intervention strategies should use TPB constructs, such as provision of motivational posters and easy access to hand-washing supplies. Among university employees, hand-hygiene behaviors were associated with reduced odds of reporting sickness in the preceding 30 days (OR $0.55 ; 95 \% \mathrm{CI}: 0.30,0.98$ ), adjusting for various risk factors. ${ }^{40}$ No results regarding the association between hand hygiene and self-reported illness were reported for bank employees.

\section{Simulation-based study}

The simulation study ${ }^{43}$ utilized a previous hand-washing intervention study on pathogen spread in an office. ${ }^{38}$ Bacteriophage tracers were used to contaminate participants' hands as a way to identify where viruses were transmitted in an office. Using these data, and hand transmission data, the effect of a hand-washing intervention was estimated for rotavirus and rhinovirus. ${ }^{43}$ The intervention consisted of increased access to hand washing facilities and surface wipes, paired with a simple educational intervention. ${ }^{38}$ The model estimated that the intervention would reduce both rotavirus and rhinovirus infection by $77 \% .{ }^{43}$ These simulations were limited, because they required a host of estimated parameters with limited data to guide parameter choice. For example, the parameters for hand-to-face contact were estimated from children's behavoir ${ }^{41}$ or from that of extremely small samples of adults. ${ }^{44}$

\section{DISCUSSION}

This systematic review is the first of its kind of hand-hygiene interventions in the nonclinical workplace. As the literature currently stands, few studies focus on hand hygiene as a method to prevent illness in office-based workplaces. The generalizability of the current literature is further limited due to the heterogeneity of interventions applied, unit of analysis (individual vs. group) and measures used, and outcomes assessed.

Despite these limitations, research indicates that hand-hygiene interventions may prevent illness in the workplace across various measures. Although alcohol-based hand sanitizer was effective in most studies, ${ }^{35,36,42,43}$ it was not in all cases. ${ }^{33,34}$ Additionally, hand hygiene with soap and water may be more protective against GI illness than for respiratory illness. ${ }^{34}$ Many GI pathogens, such as nonenveloped viruses and bacteria spores, are more resistant to inactivation by alcohol, thus requiring physical removal. ${ }^{45,46}$ Alcohol is effective against respiratory viruses, which are generally enveloped viruses, because the mechanism of action for alcohol is to denature proteins and disrupt the lipid envelope, which is required for entry into host cells. ${ }^{47}$
Current research suggests that interventions to improve hand hygiene do not have to be extraordinarily intensive. Merely providing easier access to hand-hygiene products can lead to improvements in hand-hygiene compliance. This finding is most clearly indicated in the study by Arbogast et al. ${ }^{36}$ which provided educational instructions to both intervention and control groups and nonetheless observed a larger decrease in health insurance claims related to infectious illnesses in the intervention group compared with the control group. The impact of hand-hygiene interventions had little $\mathrm{e}^{37,42}$ or no effect ${ }^{33,35,36}$ on reducing employee absences in the intervention group, compared with the control group. The lack of effect may be due to a culture of presenteeism in the workplace, influencing all employees to attend work despite illness, or to the relative rareness of severe infectious illnesses that would cause an individual to be physically unable to go to work. Previous studies may be too small to capture a reduction, based on hand hygiene, in employee absences attributable to infectious disease, owing to the relative rarity of severe illness. Receiving infection prevention education may also increase the tendency of workers to stay home, resulting in the paradoxical positive association between participating in a hand-hygiene intervention and absenteeism. ${ }^{33}$ Trials with no education arm do not report an increase in absenteeism, suggesting that increasing hand hygiene without additional education does not lead to this spurious association. ${ }^{35,36}$

Published research contains a dearth of studies on presenteeism in the workplace, and various methods to prevent it. Better ways to measure presenteeism and prevent its occurrence need to be devised. A previous systematic review on paid sick-leave policy found a large gap in the research on presenteeism. ${ }^{20}$ Of the papers investigated in our review, only two of 11 directly mentioned presenteeism as a problem. ${ }^{36,39}$

The trifecta of individual-level strategies to prevent employee illness includes hand hygiene, paid sick leave, and vaccination. Although research on vaccines in the workplace suggests that they are effective, ${ }^{48,49}$ vaccines are limited in the scope of pathogens they address. For example, a workplace influenza vaccine program will confer protection only for influenza strains for that season and not for a host of other pathogens that may be circulating during a given influenza season. Although both paid sick leave and hand hygiene are broad in the scope of pathogens they protect against, the rigorous research needed for policy recommendations in these areas is lacking. One study has shown that a lack of workplace sickleave policies is associated with increased incidence of respiratory illness. ${ }^{50}$ Additionally, paid sick leave is likely to require a large policy change at the local, state, or federal level, as employers may be loathe to implement policies individually. In the meantime, individual employers can improve hand-hygiene practices in their workplaces to protect against a variety of pathogens, potentially lowering the burden of altering workplace policies regarding absenteeism.

Arbogast et al. ${ }^{36}$ and Thompson et al. ${ }^{37}$ were the only studies that looked at economic savings due to increased access to handhygiene products. Although the results seem to be cost saving to employers, these results need to be interpreted cautiously. Currently, no other studies are available by which to compare the potential savings reported. Although productivity is reported to be lower during illness, the potential economic loss due to presenteeism remains under-researched. Additionally, economic benefits may be offset by the failure of hand-hygiene programs to prevent work absences. The work of Arbogast et al. ${ }^{36}$ was funded by a manufacturer of hand-hygiene products. Similar concerns relating to other studies included in the review are that some products or funding were provided to conduct the research, ${ }^{35,43}$ author had a disclosed conflict of interest, ${ }^{31,42}$ or existing conflicts of interest were not disclosed. ${ }^{37}$

All of the reviewed studies have limitations. The most severe limitation was self-report of hand washing. ${ }^{31-35,39,40,42}$ Some previous 
community-based studies suggest that self-reported hand washing may not validly measure the true frequency of hand washing. ${ }^{51,52}$ The potential limits of self-reported hand hygiene in offices are seen in the work of Stedman-Smith et al. ${ }^{35}$ in their comparison of handhygiene scores between intervention and control groups. Either their sample size was too small to detect a minute difference, or selfreporting does not accurately measure hand-washing practices. Arbogast et al. $^{36}$ attempted to estimate the amount of hand washing of employees by measuring the amount of product used. This measure produces only a global level of use and cannot effectively estimate individual level of use. Other ways to measure hand hygiene have been previously detailed in hand-hygiene compliance studies among healthcare workers. ${ }^{53}$

Additionally, studies relied on self-reported illness symptoms ${ }^{31-35,39,40,42}$ or absences. ${ }^{37}$ One study collected only limited samples from patients, ${ }^{32}$ and another relied on insurance claims data. ${ }^{36}$ Another issue is time between follow-up surveys. Selfreports of illness symptoms and hand-washing compliance were requested for the preceding month,31,35,39,40,42 making them susceptible to increased recall bias. Potential mistaken recall was minimized in other studies by having weekly reports. ${ }^{32-34} \mathrm{~A}$ final limitation is that some studies had higher proportion of female respondents, ${ }^{31,34,35,39,40,42}$ which may bias results because women are more likely to engage in protective hand-washing behaviors. ${ }^{54-56}$

Several new lines of research are underway that should naturally follow the findings reviewed here. Specifically, comprehensive monitoring of hand hygiene designed to obtain more accurate measures of hand-hygiene practices in the workplace is needed. In addition, attention to the social network structure of individuals in the workplace might inform intervention measures. For example, an intervention targeted at managerial/senior employees may be more effective at reducing infectious diseases; those in managerial positions are more likely to work while sick, ${ }^{15,16}$ and to have more contacts capable of transmission in the workplace, compared with other employees.

Although self-report influenza-like illness may be adequately measured by self-diagnosis, ${ }^{57,58}$ a more objective method, including having trained observers identify symptoms and obtain specimens for pathogen identification, would be preferable. With the identification of pathogens in samples, the etiology of infections can be determined, along with molecular information for tracking transmission within the workplace. Ideally, follow-up would be weekly instead of monthly, so as to reduce potential biases in recall of symptoms and hand-hygiene habits. The persistence of any hand-hygiene intervention also should be assessed, as whether the interventions suggested in this review result in long-lasting changes in behaviors among individuals in the workplace remains unclear. Last, better participant recruitment and compensation strategies should be used to increase response rate and encourage more male office employee participation. Arbogast et al..$^{36}$ used a study methodology that avoided this problem by using employee insurance claim data. Other strategies that similarly avoid gender issues could be devised. Another important measure is presenteeism and how to best assess it, in addition to absences in hand-hygiene interventions.

\section{CONCLUSION}

Hand hygiene in the workplace is a key target method for reducing communicable disease in the workplace. Although current research studies include some limitations and gaps, the overall findings indicate that hand hygiene is effective at reducing respiratory and GI illness among office employees. Our findings are compatible with widespread evidence that hand hygiene is a key measure for reducing infectious illnesses in other community settings, such as schools and daycare centers. The interventions examined here were relatively easy to implement (e.g., providing easier access to hygiene products with simple instructional information on proper hand hygiene), suggesting that the potential cost to employers may be moderate to low. Reducing illness among employees may improve productivity, raise employee morale, and generate cost savings for employers by reducing insurance claims. Enhancing hand-hygiene behaviors and education is a relatively easy and cost-effective intervention for reducing infectious diseases and their impact.

\section{References}

1. Occupational Safety and Health Administration. Guidance on preparing workplaces for an influenza pandemic. (OSHA 3327-05R 2009). Washington, DC: US Department of Labor; 2009.

2. Hovi T, Ollgren J, Haapakoski J, Amiryousefi A, Savolainen-Kopra C. Exposure to persons with symptoms of respiratory or gastrointestinal infection and relative risk of disease: self-reported observations by controls in a randomized intervention trial. Trials 2015;16:168.

3. Mohren DC, Jansen NW, Kant IJ, Galama J, van den Brandt PA, Swaen GM. Prevalence of common infections among employees in different work schedules. J Occup Environ Med 2002;44:1003-11.

4. Pejtersen JH, Feveile H, Christensen KB, Burr H. Sickness absence associated with shared and open-plan offices-a national cross sectional questionnaire survey. Scand J Work Environ Health 2011;37:376-82.

5. Bodin Danielsson C, Chungkham HS, Wulff C, Westerlund H. Office design's impact on sick leave rates. Ergonomics 2014;57:139-47.

6. Luongo JC, Fennelly KP, Keen JA, Zhai ZJ, Jones BW, Miller SL. Role of mechanical ventilation in the airborne transmission of infectious agents in buildings. Indoor Air 2016;26:666-78

7. Neely AN, Maley MP, Warden GD. Computer keyboards as reservoirs for acinetobacter baumannii in a Burn Hospital. Clin Infect Dis 1999;29:1358-9.

8. Pal S, Juyal D, Adekhandi S, Sharma M, Prakash R, Sharma N, et al. Mobile phones: reservoirs for the transmission of nosocomial pathogens. Adv Biomed Res 2015;4:144.

9. Anderson G, Palombo EA. Microbial contamination of computer keyboards in a university setting. Am J Infect Control 2009;37:507-9.

10. Boone SA, Gerba CP. The prevalence of human parainfluenza virus 1 on indoor office fomites. Food Environ Virol 2010;2:41-6.

11. Keech $M$, Beardsworth $P$. The impact of influenza on working days lost: a review of the literature. Pharmacoeconomics 2008;26:911-24.

12. Molinari NA, Ortega-Sanchez IR, Messonnier ML, Thompson WW, Wortley PM, Weintraub E, et al. The annual impact of seasonal influenza in the US: measuring disease burden and costs. Vaccine 2007;25:5086-96.

13. Schanzer DL, Zheng H, Gilmore J. Statistical estimates of absenteeism attributable to seasonal and pandemic influenza from the Canadian Labour Force Survey. BMC Infect Dis 2011;11:90.

14. Jones TF, McMillian MB, Scallan E, Frenzen PD, Cronquist AB, Thomas S, et al. A population-based estimate of the substantial burden of diarrhoeal disease in the United States; FoodNet, 1996-2003. Epidemiol Infect 2007;135:293-301.

15. Mohren DC, Swaen GM, Kant I, van Schayck CP, Galama JM. Fatigue and job stress as predictors for sickness absence during common infections. Int J Behav Med 2005; 12:11-20.

16. Keech M, Scott AJ, Ryan PJ. The impact of influenza and influenza-like illness on productivity and healthcare resource utilization in a working population. Occup Med (Lond) 1998;48:85-90.

17. Palmer LA, Rousculp MD, Johnston SS, Mahadevia PJ, Nichol KL. Effect of influenza-like illness and other wintertime respiratory illnesses on worker productivity: the child and household influenza-illness and employee function (CHIEF) study. Vaccine 2010;28:5049-56.

18. Smith A, Thomas M, Whitney H. Effects of upper respiratory tract illnesses on mood and performance over the working day. Ergonomics 2000;43:752-63.

19. Smith AP, Brice C, Leach A, Tiley M, Williamson S. Effects of upper respiratory tract illnesses in a working population. Ergonomics 2004;47:363-9.

20. Edwards $\mathrm{CH}$, Tomba GS, de Blasio BF. Influenza in workplaces: transmission, workers' adherence to sick leave advice and European sick leave recommendations. Eur J Public Health 2016;26:478-85.

21. Meilicke G, Riedmann K, Biederbick W, Muller U, Wierer T, Bartels C. Hygiene perception changes during the influenza A H1N1 pandemic in Germany: incorporating the results of two cross-sectional telephone surveys 2008-2009. BMC Public Health 2013;13:959.

22. Bagherirad M, Trevan P, Globan M, Tay E, Stephens N, Athan E. Transmission of tuberculosis infection in a commercial office. Med J Aust 2014;200:177-9.

23. Bramley TJ, Lerner D, Sames M. Productivity losses related to the common cold. J Occup Environ Med 2002;44:822-9.

24. Semmelweis IP. The etiology, concept and prevention of childbed fever. 1861. Am J Obstet Gynecol 1995;172:236-7. [Article in German].

25. Rosenthal VD, Guzman S, Safdar N. Reduction in nosocomial infection with improved hand hygiene in intensive care units of a tertiary care hospital in Argentina. Am J Infect Control 2005;33:392-7. 
26. Sickbert-Bennett EE, DiBiase LM, Willis TM, Wolak ES, Weber DJ, Rutala WA Reduction of healthcare-associated infections by exceeding high compliance with hand hygiene practices. Emerg Infect Dis 2016;22:1628-30.

27. Aiello AE, Coulborn RM, Perez V, Larson EL. Effect of hand hygiene on infectious disease risk in the community setting: a meta-analysis. Am J Public Health 2008;98:1372-81.

28. Bureau of Labor Statistics. American time use survey-2015 results. Washington, DC: U.S. Department of Labor; 2016. Available from: https://www.bls.gov/ news.release/archives/atus_06242016.pdf. Accessed November 19, 2017.

29. Moher D, Liberati A, Tetzlaff J, Altman DG. Preferred reporting items for systematic reviews and meta-analyses: the PRISMA statement. Ann Intern Med 2009;151:264-9, W64.

30. Ioannidis JP. The mass production of redundant, misleading, and conflicted systematic reviews and meta-analyses. Milbank Q 2016;94:485-514.

31. Hubner NO, Hubner C, Kramer A. Impact of health campaign on hand hygiene with alcohol-based hand rubs in a non-clinical setting. J Hosp Infect 2013; 83(Suppl 1):S23-8.

32. Savolainen-Kopra C, Haapakoski J, Peltola PA, Ziegler T, Korpela T, Anttila P, et al. STOPFLU: Is it possible to reduce the number of days off in office work by improved hand-hygiene? Trials 2010;11:69.

33. Savolainen-Kopra C, Haapakoski J, Peltola PA, Ziegler T, Korpela T, Anttila P, et al. Hand washing with soap and water together with behavioural recommendations prevents infections in common work environment: an open cluster-randomized trial. Trials 2012;13:10.

34. Hovi T, Ollgren J, Savolainen-Kopra C. Intensified hand-hygiene campaign including soap-and-water wash may prevent acute infections in office workers, as shown by a recognized-exposure -adjusted analysis of a randomized trial. BMC Infect Dis 2017:17:47.

35. Stedman-Smith M, DuBois CL, Grey SF, Kingsbury DM, Shakya S, Scofield J, et al. Outcomes of a pilot hand hygiene randomized cluster trial to reduce communicable infections among U.S. office-based employees. J Occup Environ Med 2015;57:374-80

36. Arbogast JW, Moore-Schiltz L, Jarvis WR, Harpster-Hagen A, Hughes J, Parker A. Impact of a comprehensive workplace hand hygiene program on employer health care insurance claims and costs, absenteeism, and employee perceptions and practices. J Occup Environ Med 2016;58:e231-40.

37. Thompson SJ, Rew L. The healthy workplace project: results of a hygiene-based approach to employee wellness. Am J Health Promot 2015;29:339-41.

38. Reynolds KA, Beamer PI, Plotkin KR, Sifuentes LY, Koenig DW, Gerba CP. The healthy workplace project: reduced viral exposure in an office setting. Arch Environ Occup Health 2016;71:157-62.

39. Stedman-Smith M, DuBois CL, Grey S. Workplace hand hygiene and wellness: a survey of knowledge, beliefs, and practices. Workplace Health Saf 2012;60:47785.

40. Stedman-Smith M, DuBois CL, Grey SF. Hand hygiene performance and beliefs among public university employees. J Health Psychol 2015;20:126374.

41. Beamer PI, Luik CE, Canales RA, Leckie JO. Quantified outdoor micro-activity data for children aged 7-12-years old. J Expo Sci Environ Epidemiol 2012;22:8292.
42. Hubner NO, Hubner C, Wodny M, Kampf G, Kramer A. Effectiveness of alcoholbased hand disinfectants in a public administration: impact on health and work performance related to acute respiratory symptoms and diarrhoea. BMC Infect Dis 2010;10:250.

43. Beamer PI, Plotkin KR, Gerba CP, Sifuentes LY, Koenig DW, Reynolds KA. Modeling of human viruses on hands and risk of infection in an office workplace using micro-activity data. J Occup Environ Hyg 2015;12:266-75.

44. Nicas M, Best D. A study quantifying the hand-to-face contact rate and its potential application to predicting respiratory tract infection. J Occup Environ Hyg 2008;5:347-52.

45. Weber DJ, Rutala WA, Miller MB, Huslage K, Sickbert-Bennett E. Role of hospital surfaces in the transmission of emerging health care-associated pathogens: norovirus, Clostridium difficile, and Acinetobacter species. Am J Infect Control 2010;38(5 Suppl 1):S25-33.

46. Boyce JM, Pittet D. Guideline for hand hygiene in health-care settings. Recommendations of the Healthcare Infection Control Practices Advisory Committee and the HICPAC/SHEA/APIC/IDSA Hand Hygiene Task Force. Society for Healthcare Epidemiology of America/Association for Professionals in Infection Control/Infectious Diseases Society of America. MMWR Recomm Rep 2002; 51(Rr-16):1-45, quiz CE1-4.

47. Block SS. Disinfection, sterilization, and preservation. Philadelphia: Lea \& Febiger; 1991.

48. Lee BY, Bailey RR, Wiringa AE, Afriyie A, Wateska AR, Smith KJ, et al. Economics of employer-sponsored workplace vaccination to prevent pandemic and seasonal influenza. Vaccine 2010;28:5952-9.

49. Campbell DS, Rumley MH. Cost-effectiveness of the influenza vaccine in a healthy, working-age population. J Occup Environ Med 1997;39:408-14.

50. Kumar S, Quinn SC, Kim KH, Daniel LH, Freimuth VS. The impact of workplace policies and other social factors on self-reported influenza-like illness incidence during the 2009 H1N1 pandemic. Am J Public Health 2012;102:134-40.

51. Jay LS, Comar D, Govenlock LD. A video study of Australian domestic foodhandling practices. J Food Prot 1999;62:1285-96.

52. Manun'Ebo M, Cousens S, Haggerty P, Kalengaie M, Ashworth A, Kirkwood B. Measuring hygiene practices: a comparison of questionnaires with direct observations in rural Zaire. Trop Med Int Health 1997;2:1015-21.

53. Haas JP, Larson EL. Measurement of compliance with hand hygiene. J Hosp Infect 2007;66:6-14

54. American Society of Microbiology. Public handwashing takes a hike. Washington DC: American Cleaning Institute, American Society for Microbiology: 2010. http://www.cleaninginstitute.org/public_handwashing_takes_a_hike/.

55. Anderson JL, Warren CA, Perez E, Louis RI, Phillips S, Wheeler J, et al. Gender and ethnic differences in hand hygiene practices among college students. Am J Infect Control 2008;36:361-8

56. van de Mortel T, Bourke R, McLoughlin J, Nonu M, Reis M. Gender influences handwashing rates in the critical care unit. Am J Infect Control 2001;29:395-9.

57. Macintyre S, Pritchard C. Comparisons between the self-assessed and observerassessed presence and severity of colds. Soc Sci Med 1989;29:1243-8.

58. Larson EL, Lin SX, Gomez-Pichardo C, Della-Latta P. Effect of antibacterial home cleaning and handwashing products on infectious disease symptoms: a randomized, double-blind trial. Ann Intern Med 2004;140:321-9. 